\title{
CUARENTEÑO, NUEVA VARIEDAD DE FRIJOL DE TIPO CACAHUATE PARA EL ESTADO DE JALISCO, MÉXICO
}

\section{CUARENTEÑO NEW CRANBERRY BEAN CULTIVAR FOR THE STATE OF JALISCO, MÉXICO}

\author{
Rogelio Lépiz-Ildefonso ${ }^{1 *}$, José de J. López-Alcocer ${ }^{1}$, Carlos \\ González-Rivas ${ }^{2}$ y Eduardo Rodríguez-Guzmán ${ }^{1}$
}

\begin{abstract}
${ }^{1}$ Centro Universitario de Ciencias Biológicas y Agropecuarias, Universidad de Guadalajara. Camino Ramón Padilla Sánchez 2100. 44600, Nextipac, Zapopan, Jalisco. ${ }^{2}$ Campo Experimental Santiago Ixcuintla, Instituto Nacional de Investigaciones Forestales, Agrícolas y Pecuarias. Km. 6 Carretera Internacional México-Nogales, Santiago Ixcuintla, Nayarit.

*Autor para correspondencia (rlepiz@cucba.udg.mx)
\end{abstract}

El estado de Jalisco, México, en el trienio 2012-2014 tuvo una población promedio de 7.6 millones de personas (INEGI, 2015) y un consumo promedio anual de frijol común (Phaselus vulgaris L.) estimado en 76,773 t. En el mismo periodo sólo se produjeron en la entidad 15,576 t anuales de esta leguminosa (SIAP, 2016), por lo que fue necesario importar 61,197 t (80 \%) de los estados de Sinaloa, Zacatecas y Durango para cubrir las necesidades de la población jalisciense.

Para impulsar la producción de la leguminosa en Jalisco, se requiere la siembra de frijol arbustivo de alto potencial de rendimiento que permita: a) incrementar la superficie de siembra en las regiones Centro, Sur, Valles y parte de los Altos de Jalisco, donde existen condiciones de clima y suelo favorables para la producción, y b) hacer un uso eficiente de componentes tecnológicos y manejo tecnificado del cultivo. De esta forma se pueden cosechar hasta $2 \mathrm{t}$ ha-1 de frijol bajo condiciones de temporal (secano) con variedades de tipo III (Lépiz et al., 2001).

Con este propósito, en el año 2000 el Centro Universitario de Ciencias Biológicas y Agropecuarias (CUCBA) de la Universidad de Guadalajara (UDG) implementó un proyecto orientado al desarrollo de variedades de frijol de alto rendimiento y grano preferente para las regiones con alto potencial productivo de esta especie en Jalisco. El proyecto inició con la introducción de germoplasma nacional e internacional, para identificar progenitores útiles como fuente de genes de resistencia a bacteriosis de halo (Pseudomonas syringae pv. phaseolicola) y antracnosis (Colletotrichum lindemuthianum). Estos donadores de resistencia, se cruzaron con variedades tipo Peruano de Sinaloa o Cacahuate, de alta demanda entre productores y consumidores de Jalisco, pero susceptibles a las enfermedades mencionadas (Lépiz et al., 2001; Lépiz et al., 2016).
Los métodos de mejoramiento genético que se aplicaron para generar la variedad Cuarenteño, fueron hibridación y selección. Como progenitor donante de los genes de resistencia a bacteriosis de halo y antracnosis se utilizó a la línea SUG 55, de grano grande (42 g en 100 semillas) tipo Cacahuate Bola. Esta línea provino del Programa de Frijol del Centro Internacional de Agricultura Tropical (CIAT), que se introdujo a Jalisco en el año 2000. Como progenitor con demanda en el mercado local y nacional, se utilizó la variedad Cacahuate Bola Criollo, de grano grande (43 g en 100 semillas) y susceptible a bacteriosis de halo y antracnosis. Ambos progenitores pertenecen a la raza Nueva Granada del acervo genético Andino.

Las hibridaciones para obtener la cruza simple con código CBA-26, se realizaron en los años 2003 y 2004; y luego de 2004 a 2008 se llevó a cabo el avance generacional y selecciones individuales en las poblaciones segregantes. La selección de líneas se realizó mediante el método genealógico y el método masivo; el método genealógico se aplicó en Zapopan en el ciclo de temporal (julio a octubre) y el avance masivo sin selección (Lépiz et al., 2016) en el ciclo otoño-invierno (noviembre a febrero) en el Campo Experimental Santiago Ixcuintla, Nayarit, del Instituto Nacional de Investigaciones Forestales, Agrícolas y Pecuarias (INIFAP).

La línea uniforme con genealogía CBA-26-36-M-2-M que dio origen a la variedad Cuarenteño, se obtuvo en el año 2007. Las primeras evaluaciones de la línea por adaptación y rendimiento, se realizaron en la estación experimental "Las Agujas" de Zapopan, Jalisco; y entre 2008 y 2010 (Cuadro 1), por su buen comportamiento agronómico, se codificó como UGCB-3. La línea se evaluó en un ensayo de rendimiento regional en 2011 y 2012 junto con otros materiales de diferente tipo de grano y alto rendimiento (Cuadro 1). La caracterización de la línea UGCB-3 se efectuá con base en los descriptores de la Unión Internacional para la Protección de 
Cuadro 1. Indicadores de adaptación, resistencia a enfermedades y rendimiento de grano de tres variedades de frijol en localidades de Jalisco.

\begin{tabular}{lccccccccc}
\hline Genotipo & DF & ADV & BH & BC & ANT & VAG & DM & Z 2010 (kg ha-1) & Seis Amb $\left(\mathrm{kg} \mathrm{ha}^{-1}\right)$ \\
\hline Cuarenteño & 40 & 2.5 & 2.0 & 3.5 & 2 & 2.0 & 88 & 1720 & 1487 \\
Azufrado Bolita & 44 & 3.0 & 3.0 & 3.7 & 2 & 3.0 & 92 & 1219 & 1216 \\
Azufrado Higuera (T) & 40 & 6.0 & 8.0 & 7.0 & 7 & 7.5 & 90 & 476 & 834 \\
\hline
\end{tabular}

Escala de evaluación (variables agronómicas): 1, 2, 3 = bueno/resistente; 4, 5, 6 = intermedio; 7, 8, 9 = deficiente/susceptible. DF, días a floración; ADV, adaptación vegetativa; $\mathrm{BH}$, bacteriosis de halo; BC, bacteriosis común; ANT, antracnosis; VAG, valor agronómico (vigor, sanidad, potencial de rendimiento); Z 2010, indicadores de adaptación, resistencia a enfermedades y rendimiento de grano en Zapopan 2010; Seis Amb, rendimiento medio en seis ambientes; $T$, variedad testigo.

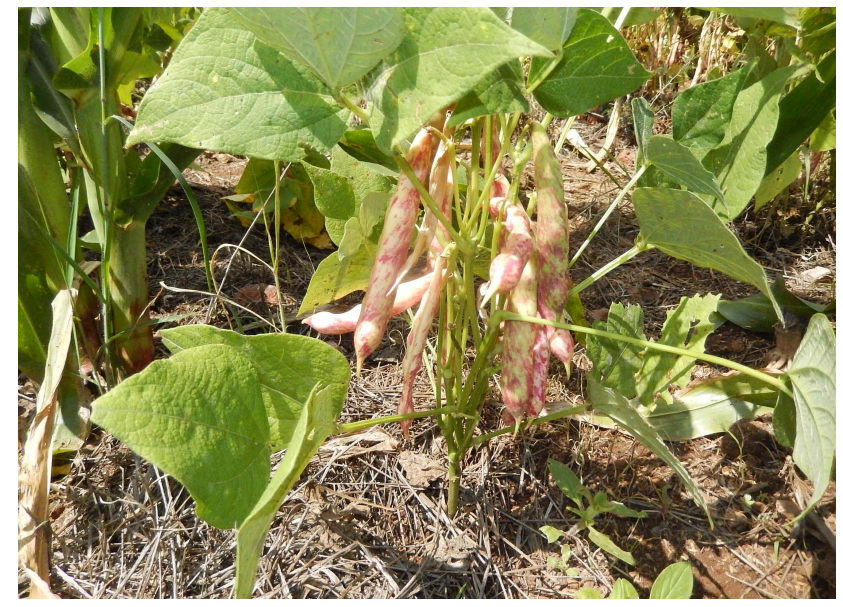

Figura 1. Planta y vainas de la variedad de frijol Cuarenteño en madurez fisiológica.

Obtenciones Vegetales (UPOV, 2012). En 2014 se solicitó al Servicio Nacional de Inspección y Certificación de Semillas (SNICS) el registro de la línea UGCB-3 de frijol cacahuate bola como nueva variedad, línea derivada de la cruza de SUG 55 x Cacahuate Bola Criollo con genealogía CBA-2636-M-2-M. El título de obtentor se emitió el 26 de enero de 2015 con registro 1304 y nombre oficial de Cuarenteño.

La variedad Cuarenteño es de hábito de crecimiento determinado tipo 1a (Figura 1), ciclo biológico precoz (40 d a floración y 88 d a madurez), resistente a roya (Uromyces appendiculatus var. appendiculatus), bacteriosis de halo y antracnosis. El grano es de color crema rayado de marrón con hilio pigmentado de café, de forma elíptica truncada, con peso de $44 \mathrm{~g}$ en 100 semillas y preferencia alta en el mercado (Figura 2). En condiciones de temporal en las regiones Centro, Valles, Sur y Altos de Jalisco (Ixtlahuacán del Río, Cuquío, Yahualica), la variedad Cuarenteño debe sembrarse entre el 25 de julio y el 10 de agosto (Lépiz et al., 2015). En el Centro Universitario de Ciencias Biológicas y Agropecuarias ubicado en Zapopan, Jalisco, se dispone de semilla de la nueva variedad.

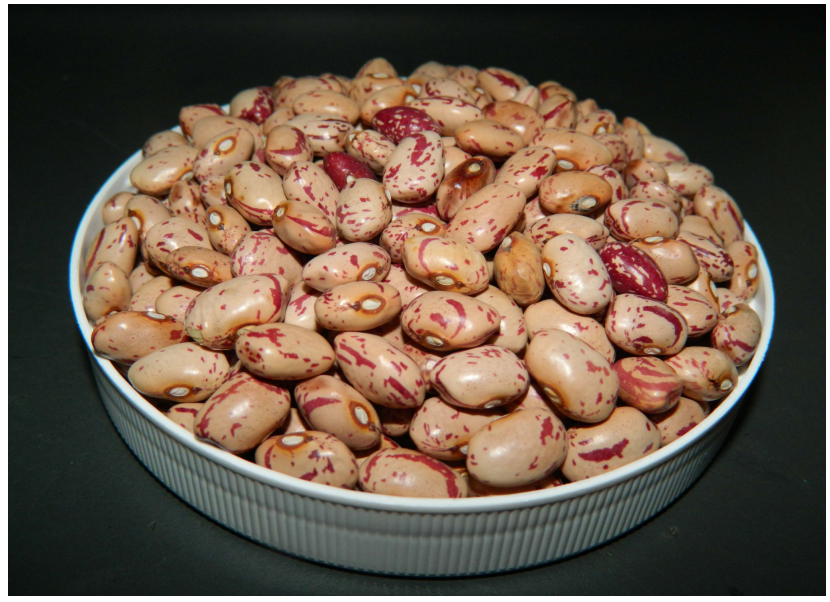

Figura 2. Color y forma de los granos de la variedad de frijol Cuarenteño.

\section{BIBLIOGRAFÍA}

INEGI, Instituto Nacional de Estadística, Geografía e Informática (2015) Población por Entidad Federativa. http://cuentame.inegi.org.mx/ monografias/informacion/jal/poblacion/ (Abril 2016).

Lépiz R., E. López, J. L. Martínez, R. Rodríguez, S. de la Paz y M. Morales (2001) Desarrollo de variedades de frijol para el occidente de México. Scientia-CUCBA 3:86-93.

Lépiz R., S. Sánchez, E. López, J. J. López, I. Chavarín y K. Meza (2015) El Cultivo de Frijol en Jalisco. Tecnología para Altos Rendimientos UDG, CUCBA. Zapopan, Jalisco, México $54 \mathrm{p}$.

Lépiz R., J. J. López, C. González y E. Rodríguez (2016) Azufrado Bolita, nueva variedad de frijol para el Estado de Jalisco, México. Revista Fitotecnia Mexicana 39:101-103.

SIAP, Servicio de Información Agroalimentaria y Pesquera (2016) Anuario Estadístico de la Producción Agrícola. Cierre de la producción agrícola por cultivo en Jalisco. http:/www.siap.gob.mx/cierrede-la-producción-agrícola-por-estado (Marzo 2016).

SNICS, Servicio Nacional de Inspección y Certificación de Semillas (2013) Guía Técnica para la Descripción Varietal en Frijol (Phaseolus vulgaris L.). SNICS, SAGARPA. Tlalnepantla, Estado de México $24 \mathrm{p}$.

UPOV, Unión Internacional para la Protección de las Obtenciones Vegetales (2012) Directrices para la Ejecución del Examen de la Distinción, la Homogeneidad y la Estabilidad. Judía común (Phaseolus vulgaris). Ginebra, Suiza. 47 p. http://www.upov.int/edocs/tgdocs/ es/tg012.pdf (Febrero 2016). 